\title{
Relationship of Pain, Disability and Quality of Life in Individual with Neck and Shoulder Pain
}

\author{
Ho-Chung Jeon', Kyung-Won Yang', Ka-Hoe Kim², Seul-Ki Kim², Ho-Kwon Kim², Jin-II Seo², Gi-Won Kim³, June-Sun Kim \\ ${ }^{1}$ Major in Rehabilitation Science, Department of Public Health Science, Korea University Graduate School, Seoul; ${ }^{2}$ Department of Physical Therapy, \\ College of Health Science, Korea University, Seoul; ${ }^{3}$ Department of Physical Therapy, College of Health Science, Korea University, Research Institute \\ of Health Sciences, Korea University; ${ }^{4}$ Department of Physical Therapy, College of Health Science, Korea University, Research Institute of Health \\ Sciences, Korea University, Department of Public Health Sciences, Graduate School, Korea University Korea
}

Purpose: This study was to investigate the correlation between pain, disability and quality of life among adolescents and office workers with neck and shoulder pain.

Methods: Twenty-four subjects (mean age $=24.92$ years, $S D=3.94$, range $=20-37$ ) with neck and shoulder pain participated in this study. The outcome measures of the study were visual analogue scale (VAS), neck disability index (NDI), shoulder pain and disability index (SPADI), short form-36 (SF-36) for neck and shoulder pain and disability, quality of life. Pearson's correlation and Speaman's rank correlation were used to measure the association between VAS and NDI, SPADI, SF-36.

Results: The VAS showed a positive correlation between weak to moderate with the NDI and SPADI, but no significantly correlated $(\rho=0.34, \rho=0.25)$. The moderate positive correlation and significant correlation were observed between NDI and SPADI ( $\rho=0.43$, $p<0.05)$. The PCS of SF-36 was significantly negative correlated with the VAS $(\rho=-0.24)$, NDI and SPADI $(\rho=-0.63, \rho=-0.59, p<0.05)$. Conclusion: The pain and disability of neck and shoulder has closely relevance. And, the pain and disability of neck and shoulder has a negative impact on the quality of life.

Keywords: Pain, Disability, Quality of life

\section{서 론}

목과 어깨 통증은 청소년과 사무직 근로자 외에도 현대인에게서 빈번하게 일어나는 건강 문제 중 하나이다.' 무거운 가방을 메거나, 장 시간 책상에 앉아있는 학생과 직장인들의 경우 쉽게 목의 피로와 목 어깨의 통증을 호소하며, 증상을 갖고 있는 대부분은 목이 과도하게 전방위 된 비정상적인 자세를 취하고 있다. 근래에는 스마트 폰이나 휴대형 컴퓨터와 같은 소형 영상 단말기의 대중화로 인하여 거북 목 자세 및 목, 어깨의 통증을 호소하는 사람들이 점차 증가하고 있는 추세이다. ${ }^{2}$ 부적절한 베개 사용이나 운동 부족으로 나타나는 통증의 양상 및 비정상적인 자세 역시 유사하게 나타난다. 목과 어깨 근육의 경직 및 비정상적인 자세는 경직 부위의 통증과 두통을 유발하고 이 것은 가동범위의 제한을 일으킨다. ${ }^{3}$ 근육의 경직으로 야기된 비정상 적인 자세는 통증 원인 부위 외에도 턱 관절통이나 긴장성 두통과 같

\section{은 근골격계 통증 증후군의 주요한 원인이 된다. ${ }^{4}$}

정의에 따라 구체적인 질환명이 다른 경우도 있으나, 일반적으로 명명하는 목 통증의 경우 1 년 유병률이 매년 전체 인구의 $1 / 3$ 이상이 며 이들은 지속적인 만성 통증과 재발의 위험을 가지고 있다. ${ }^{5}$ 목 통 증은 반복적으로 발생되어 쉽게 만성화가 진행되며, 잘 호전되지 않 고 시간의 경과에 따라 예후가 나쁘다. 만성화된 목 통증은 어깨 통 증을 수반하는 경우가 많으며, 이는 통증을 지속시키고, 삶의 질 저 하를 야기하게 된다. ${ }^{78}$ 일상 생활과 관련하여 목 또는 어깨 통증으로 인한 신체 기능을 평가하는 객관적 지표의 대표적인 예로 목통증지 수(neck disability index, NDI)와 어깨통증장애지수(shoulder pain and disability index, SPADI)가 있다. 목 통증 자가보고측정 설문지인 NDI 는 심한 목 통증 및 편타손손상(whiplash injury)으로 인한 통증 및 기 능 장애 판별에 용이하며, 환자의 현재 일상생활 정도 및 3 년간의 예 후를 평가 할 수 있다.910 SPADI는 일상생활 내에서 통증을 포함한 복
Received Sep 20, 2016 Revised Oct 4, 2016

Accepted Oct 12, 2016

Corresponding author Gi-Won Kim, June-Sun Kim

E-mail rldnjs44@korea.ac.kr, junokim@korea.ac.kr
Copylight (C)2016 The Korea Society of Physical Therapy

This is an Open Access article distribute under the terms of the Creative Commons Attribution Non-commercial License (Http:// creativecommons.org/license/by-nc/4.O.) which permits unrestricted non-commercial use, distribution, and reproduction in any medium, provided the original work is properly cited. 
합적인 어깨 기능 장애를 평가하는 설문지로써 삶의 질과 관련하여 간단하고 정확하게 측정해 낼 수 있다.8.11 이 두가지 측정 도구를 이용 한 선행 연구에서 만성 통증과 삶의 질의 역상관 관계를 보고하였으 며, 통증 감소를 위한 치료 및 교육이 삶의 질을 증진시킨다는 것을 보고하고 있다.1,12 다시 말해서, 목과 어깨의 만성 통증은 개인의 삶 의 질 감소와 직무능력 감퇴를 야기하고 나아가 사회적, 경제적 손실 을 발생시키는 중요한 원인 중 하나이다.13.14

건강관련 삶의 질이란 단순히 신체 질병이 없는 건강만을 의미하는 것이 아니라 정신적, 사회적 안녕까지 포함하는 것으로 최근 건강관련 연구에서 임상가, 연구자, 그리고 보건 정책 전문가 등에게 중요한 의미 를 갖는 개념이다.12,15,16 건강관련 삶의 질을 측정하는 도구들은 다양하 다. 세계보건기구의 삶의 질 척도(world health organization quality of life assessment instrument, WHOQOL), short form-36 (SF-36) 등이 대표적인 척도이며 노인, 어린아이, 특정 질환을 가지고 있는 사람들을 위한 삶 의 질 척도 등이 있다.1718 SF-36 같은 경우 신체적, 정신적 내용을 포함 한 36 개의 문항으로 이루어져있으며, 타당도와 신뢰도가 충분히 검증 된 평가 방법이다.19,20 SF-36은 대규모 인구집단 연구에서도 사용이 가 능하며, 동질성을 갖는 집단의 건강과 삶의 질 연구에 적합한 평가방 법으로 많은 보건관련 분야 임상 및 정책 연구에 사용되고 있다.21.22

목과 어깨 통증이 있는 사람들의 통증 정도와 장애 지수의 관련성 을 연구한 연구들은 있으나통증, 장애 정도와 삶의 질의 관련성을 본 연구는 드물다. 따라서 본 연구는 목과 어깨 통증이 있는 사람들 의 통증과 장애 정도, 삶의 질 사이의 관련성을 파악하고자 하였다.

\section{연구 방법}

\section{1. 연구 대상자 모집과 설문 조사 과정}

본 연구는 18 세 이상 40 세 미만의 성인 중에서 목과 어깨에 통증을 호소하거나 이로 인해 일상생활에서 불편함이 느껴지는 사람을 대 상으로 하였으며 목이나 어깨의 통증으로 의학적 진단을 받은 사람 은 아니었다. 연구 대상자 모집과 설문 수집 과정은 K대학교 기관생 명윤리위원회의 승인 이후 2015년 9월 1일부터 11일까지 포털 및 교내 게시판에 모집 공고를 게시하였다. 연구대상자 수는 $\mathrm{G}^{*}$ power 3.1 프 로그램을 활용하여 상관관계 분석을 위해 검정력 0.8 , 유의수준 0.05 , 효과크기 0.5 로 하였을 때 필요한 표본수는 총 26 명이었다. 자발적 참 여를 원한 대상자는 총 24 명이었고, 목과 어깨의 통증과 삶의 질 사이 의 상관관계에 대한 설문의 목적과 진행 방법 등에 대한 자세한 설명 을 듣고 난 후, 실험 참여 동의서를 작성한 후 설문에 응답하였다. 대 상자들이 설문을 작성하는데 걸린 시간은 평균 30 분 정도였으며 설 문 중간 이해가 되지 않는 부분은 연구원에게 질문하도록 하였다.

\section{2. 실험방법}

1) 측정도구

(1) 일반적 특성

대상자의 일반적 특성은 나이, 키, 몸무게로 구성하였다.

\section{(2) 시각상사척도(visual analogue scale, VAS)}

목과 어깨의 통증 정도를 파악하기 위해 VAS를 사용하였다. VAS 는 $10 \mathrm{~cm}$ 길이의 선 위에 왼쪽 끝부분은 "통증이 전혀 없는 상태"로, 오른쪽 끝부분은 “아주 심한 통증”으로 표시되어 있다. 대상자가 주 관적으로 느끼는 통증 정도를 선 위에 표시하게 한 후 왼쪽 끝의 시 작점에서 대상자가 표시한 지점까지의 거리를 자로 측정하여 점수화 하는 방법으로 높은 재현성을 보인다. VAS의 검사-재검사 신뢰도 (test-retest reliability)는 Li 등23의 선행연구 결과 급간내상관계수(intraclass correlation coefficient, ICC)는 0.70-0.83였다.

\section{(3) 목통증지수(neck disability index, NDI)}

목 통증이 일상생활능력에 어떤 영향을 미치는지 알아보기 위해 $\mathrm{NDI}$ 를 사용하였다. 현재 통증의 정도, 자기관리, 물건 들어올리기, 책 읽기, 두통, 집중력, 일하기, 운전, 잠자기, 여가활동 등 10 개의 항목으 로 구성되어 있다. 각 항목은 0 점부터 5 점으로 0 점은 가장 가벼운 정 도의 제한, 5 점은 가장 심한 정도의 제한이 있음을 나타낸다. $0-4$ 점은 "이상 없음", 5-14점은 “가벼운", 15-24점은 “중간 정도”, 25-34점은 “심 한", 35점 이상은 “심각한, 완전한” 제한이 있음을 알려준다. $\mathrm{NDI}$ 는 목 통증이 있는 환자가 스스로 생활 속에서 갖는 제한점을 평가할 수 있 도록 만들어진 최초의 설문지로 높은 신뢰도, 타당도, 민감도를 갖는 다. 크론바하 알파계수(cronbach's alpha coefficient)를 이용해 측정한 내적 일치도는 0.8 , 검사-재검사 신뢰도는 0.89 였다..$^{24}$

\section{(4) 어깨통증장애지수(shoulder pain disability index, SPADI)}

어깨 통증 정도와 어깨 통증이 일상생활능력에 어떤 영향을 미치 는지 알아보기 위해 SPADI를 사용하였다. SPADI는 통증과 장애를 측정하는 척도를 구분해 놓고 있다. 통증 척도에는 일반적인 통증, 통 증이 있는 쪽으로 누울 때, 높은 선반의 물건에 팔을 뻗을 때, 목 뒤를 잡을 때, 통증이 있는 팔로 밀 때 등 5 가지 항목으로 구성되어 있다. 0 점부터 10 점까지로 구성되어있고, 0 점은 통증 없음, 10 점은 가장 심한 통증을 나타낸다. 장애척도는 머리를 감을 때, 등을 닦을 때, 내의나 겉옷을 입을 때, 단추가 있는 셔츠를 입을 때, 바지를 입을 때, 높은 선 반 위에 물건을 놓을 때, $4.5 \mathrm{~kg}$ 의 무거운 물체를 들어 나를 때, 바지 뒷 주머니에서 무엇인가를 꺼낼 때의 8 가지 항목으로 구성되어 있다. $\mathrm{SPADI}$ 는 일상 생활에서 자주 하는 동작들이 문항으로 되어있어 스 스로 통증과 장애 정도를 진단하기에 용이하게 했다. 0 점부터 10 점까 
지로 구성되어 있고, 0 점은 힘이 들지 않음, 10 점은 도움 없이 할 수 없 음을 나타낸다. 통증과 장애척도의 점수를 각각 백분위 환산한 점수 와 각 척도의 점수를 합하여 백분위로 환산한 점수를 사용한다. 크 론바하 알파 계수를 이용해 측정한 내적 일치도는 0.95 , 검사-재검사 신뢰도는 0.66 이었다. ${ }^{8}$

\section{(5) 삶의 질 척도(36-item short form health survey, SF-36)}

본 연구에서 사용된 SF-36은 환자 스스로 신체와 정신과 관련된 항 목들을 통해 삶의 질을 평가할 수 있는 설문지로 Optum에서 제공하 고 있는 SF-36v2이다. 이는 현재 가장 많이 쓰이고 있는 버전이다. 설문 지는 총 8 개의 영역으로 구성되어 있고 각각의 영역에서 평가가 이루 어진다. 각각의 영역은 신체적 기능(physical functioning, $\mathrm{PF}$ ), 신체적 역 할(role physical, RP), 신체적 통증(bodily pain, BP), 전체적 건강(general health, GH), 신체 활력(vitality, VT), 사회적 기능(social functioning, SF), 감정적 역할(role emotion, $\mathrm{RE}$ ), 정신적 건강(mental health, $\mathrm{MH}$ ) 등으로 총 36 개의 문항으로 구성되어있다. 각 영역은 0점부터 100 점 사이로 구성되며, 점수가 높을수록 건강한 상태를 나타내고, 점수가 낮을수 록 건강하지 않고 삶에 제한이 있는 상태를 말한다. 각 영역에 대한 내 적 일치도는 크론바하 알파계수 0.78 에서 0.93 사이였다.25

\section{2) 통계 분석}

연구 대상자의 일반적 특성과 목과 어깨의 통증, 장애 정도, 삶의 질은 정규성 검증을 위해 Shapiro-Wilk 검정하였다. 그 결과 대상자의
나이와 NDI, SPADI total, SF-36 중 신체적 영역 척도(physical component scale, PCS)는 정규분포를 가정하지 않아 기술통계 결과 중위수 와 범위로 나타내었고, 그 외 나머지 일반적인 특성과 VAS, SPADI 중 pain 영역, SF-36 하위 영역들 중 정규분포를 가정한 항목들(BP, GH, $\mathrm{VT}, \mathrm{SF}, \mathrm{MH}, \mathrm{MCS})$ 은 기술 통계하여 평균과 표준편차로 나타내었다.

통증과 장애 정도, 삶의 질 관련성을 설명하기 위해 정규분포를 가 정하는 변수들은 Pearson 상관관계 분석을 실시하였고 정규분포를 가정하지 않는 변수들은 하나라도 정규분포 하지 않으면 Spearman 순위 척도로 상관관계를 분석하였다. Pearson 상관관계 분석 결과는 일반적인 해석기준을 적용하여 0.1 이하는 거의 무시할만한 상관성 을, 0.1-0.3은 약한 상관성을, 0.3-0.7은 중간 정도의 상관성을, 0.7-1.0은 강한 상관성을 나타내는 것으로 해석하였다. Spearman 순위 척도는 Pearson 상관관계와는 달리 선형적 상관관계의 해석이 아니라 한 변 수가 증가할 때 다른 변수가 증가하는지 감소하는지를 나타내는 것 으로 해석하였다.

수집된 자료는 SPSS version 18.0을 이용하여 분석하였고 통계적 유 의수준은 0.05 로 하였다.

\section{결 과}

\section{1. 통증, 장애 정도, 삶의 질의 기술통계와 정규성 검정}

대상자의 일반적인 특성과 통증, 장애 정도, 삶의 질은 Table 1에 나 타내었다. 목과 어깨의 통증을 측정한 VAS는 정규분포를 가정하였

Table 1. Descriptive statistics and normality test of participants with neck and shoulder pain

\begin{tabular}{|c|c|c|c|c|}
\hline General characteristics & Mean \pm SD & Median (range) & Shapiro-Wilk & $p$ \\
\hline Age (yr) & $24.92 \pm 3.94$ & $24.00(20.00-37.00)$ & 0.84 & 0.001 \\
\hline Height (cm) & $170.28 \pm 8.01$ & & 0.95 & 0.218 \\
\hline Weight (kg) & $60.75 \pm 10.33$ & & 0.97 & 0.679 \\
\hline VAS (cm) & $5.78 \pm 1.59$ & & 0.98 & 0.906 \\
\hline $\mathrm{NDI}$ & $9.13 \pm 5.19$ & $7.50(3.00-24.00)$ & 0.89 & 0.012 \\
\hline SPADI (total) & $19.96 \pm 17.44$ & $14.00(0-62.30)$ & 0.86 & 0.003 \\
\hline SPADI (pain) & $34.58 \pm 21.45$ & & 0.95 & 0.324 \\
\hline SPADI (disability) & $11.30 \pm 16.79$ & $5.05(0-60.00)$ & 0.72 & $<0.001$ \\
\hline PF & $52.59 \pm 4.19$ & $55.00(44.60-57.10)$ & 0.86 & 0.003 \\
\hline $\mathrm{RP}$ & $46.23 \pm 8.56$ & $49.20(28.00-56.20)$ & 0.88 & 0.010 \\
\hline $\mathrm{BP}$ & $41.30 \pm 8.03$ & & 0.94 & 0.158 \\
\hline $\mathrm{GH}$ & $41.02 \pm 8.82$ & & 0.96 & 0.405 \\
\hline VT & $43.45 \pm 6.07$ & & 0.97 & 0.629 \\
\hline SF & $39.28 \pm 8.54$ & & 0.92 & 0.068 \\
\hline RE & $41.70 \pm 14.06$ & $44.80(23.70-55.30)$ & 0.76 & $<0.001$ \\
\hline $\mathrm{MH}$ & $40.50 \pm 8.11$ & & 0.94 & 0.151 \\
\hline PCS & $46.30 \pm 5.96$ & $48.00(34.80-53.40)$ & 0.90 & 0.020 \\
\hline MCS & $38.76 \pm 9.86$ & & 0.95 & 0.272 \\
\hline
\end{tabular}

SD: standard deviation, VAS: visual analogue scale, NDI: neck disability index, SPADI: shoulder pain disability index, PF: physical functioning, RP: role physical, BP: bodily pain, GH: general health, VT: vitality, SF: social functioning, RE: role emotion, MH: mental health, PCS: physical component scale, MCS: mental component scale. 
고 대상자들의 통증 정도는 평균 $5.78 \mathrm{~cm}$ 였다. 목의 장애 정도를 나타 내는 NDI는 정규분포를 가정하지 않았고 평균 9점 이상이었으며, 어 깨의 장애 정도를 나타내는 SPADI는 pain은 정규분포를 가정하였고 disability와 total은 정규분포를 가정하지 않았으며 전체 평균 $19 \%$ 이 상이었다. 대상자의 건강 관련 삶의 질은 평균 39.28-52.59점 사이였 고, $\mathrm{SF}-36$ 의 8 개 하위 분류 중 $\mathrm{BP}, \mathrm{GH}, \mathrm{VT}, \mathrm{SF}, \mathrm{MH}$ 와 MCS는 정규분포 를 가정하였으며 $\mathrm{PF}, \mathrm{RF}, \mathrm{RE}$ 와 PCS는 정규분포를 가정하지 않았다. 점수가 가장 낮은 항목은 SF였고 가장 높은 항목은 $\mathrm{PF}$ 였다.

\section{2. 통증과 장애 정도의 상관관계}

목과 어깨의 통증과 장애 정도를 측정한 VAS와 $\mathrm{NDI}, \mathrm{SPADI}$ 는 양 의 상관관계를 나타내었다. VAS와 $\mathrm{NDI}$ 는 중간 정도의 상관성 $(\rho=0.34)$ 을, VAS와 SPADI (total)는 약한 상관성 $(\rho=0.25)$ 을 보였으나 모두 통계적으로 유의하지 않았다 $(\mathrm{p}>0.05)$. NDI와 SPADI는 중간 정 도의 상관관계 $(\rho=0.43)$ 를 나타내었고 통계적으로 유의한 차이를 나 타내었다 $(\mathrm{p}<0.05)($ Table 2$)$.

\section{3. 삶의 질과의 상관관계}

목과 어깨의 통증과 장애 정도를 삶의 질과 상관관계 분석한 결과

Table 2. Correlation coefficient between VAS, NDI, and SPADI subscales

\begin{tabular}{lllllc}
\hline & VAS & NDI & $\begin{array}{c}\text { SPADI } \\
\text { (total) }\end{array}$ & $\begin{array}{c}\text { SPADI } \\
\text { (pain) }\end{array}$ & $\begin{array}{c}\text { SPADI } \\
\text { (disability) }\end{array}$ \\
\hline VAS & 1 & & & & \\
NDI & 0.34 & 1 & & & \\
SPADI (total) & 0.25 & $0.43^{*}$ & 1 & & \\
SPADI (pain) & 0.39 & 0.38 & $0.96^{*}$ & 1 & \\
SPADI (disability) & 0.18 & $0.45^{*}$ & $0.92^{*}$ & $0.83^{*}$ & 1 \\
\hline
\end{tabular}

VAS: visual analogue scale, NDI: neck disability index, SPADI: shoulder pain disability index. ${ }^{*} \mathrm{p}<0.05$.
는 Table 3 에 정리하였다. SF-36은 8 개 하위 영역으로 나눈 것과 신체 적 영역 척도(PCS), 정신적 영역 척도(MCS)로 나눈 것을 모두 분석하 였다.

VAS는 SF-36의 PF를 제외한 모든 영역과 음의 상관관계를 나타내 었고 RP, BP, GH, SF와는 중간 정도의 음의 상관관계를 나타내었고 통 계적으로 유의하였으나 $(\mathrm{p}<0.05)$ 그 외 항목 $(\mathrm{PF}, \mathrm{VT}, \mathrm{RE}, \mathrm{MH}, \mathrm{PCS}$, $\mathrm{MCS})$ 은 약한 상관 관계를 나타내었고 통계적으로 유의하지 않았다 $(\mathrm{p}>0.05)$ (Table 3).

$\mathrm{NDI}$ 는 SF-36의 모든 영역과 음의 상관 관계를 가지고 있었고 VAS 와 같이 RP, BP, GH, SF와는 중간 정도의 음의 상관관계를 나타내었고 통계적으로 유의하였다 $(\mathrm{p}<0.05)$ (Table 3). 특히 NDI는 PCS와 $\rho=-0.63$ 의 음의 상관관계를 나타내었고 통계적으로 유의하였으나 MCS와는 낮은 음의 상관관계를 나타내었고 통계적으로 유의하지 않았다.

SPADI는 SF-36의 3 개 항목(VT, RE, MCS)을 제외한 모든 영역과 음 의 상관관계를 나타내었고 $\mathrm{BP}$ 와 PCS영역에서 중간 정도의 음의 상 관관계를 나타내었고 통계적으로 유의하였다 $(\mathrm{p}<0.05)($ Table 3$)$.

\section{고 찰}

본 연구는 목과 어깨 통증이 있는 사람들의 통증과 장애 정도, 삶 의 질 사이의 관련성을 파악하고자 하였다.

본 연구 대상자들의 통증 정도는 평균 VAS $5.78 \mathrm{~cm}, \mathrm{NDI} 9.13$ 점, SPADI 19.96\%로 다른 선행연구에 비하여 통증의 정도는 심하다고 응 답한 반면, 상대적으로 불편함이나 장애 지수는 낮은 것으로 나타났 다. $\mathrm{Ma}$ 등 ${ }^{26}$ 은 컴퓨터 업무가 많은 직장인들을 대상으로 한 작업관련 근골격계 통증(work-related musculoskeletal pain) 연구에서 본 실험과 동일한 측정 도구를 사용하여 비슷한 결과를 얻었다. 본 연구와 $\mathrm{Ma}$ 등 26 의 연구 대상자들의 연령대(본 연구: 평균 24.5 세, $\mathrm{Ma}$ 등: 평균 33.3

Table 3. Correlation coefficient between VAS, NDI, SPADI, and SF-36 subscales

\begin{tabular}{|c|c|c|c|c|c|}
\hline & VAS & $\mathrm{NDI}$ & SPADI (total) & SPADI (pain) & SPADI (disability) \\
\hline PF & 0.23 & -0.28 & -0.22 & -0.09 & -0.39 \\
\hline $\mathrm{RP}$ & $-0.41^{*}$ & $-0.64^{*}$ & -0.25 & -0.25 & -0.27 \\
\hline $\mathrm{BP}$ & $-0.49^{*}$ & $-0.47^{\star}$ & $-0.48^{*}$ & $-0.47^{*}$ & $-0.62^{*}$ \\
\hline $\mathrm{GH}$ & $-0.45^{\star}$ & $-0.55^{\star}$ & -0.36 & -0.35 & -0.34 \\
\hline VT & -0.2 & -0.17 & 0.10 & 0.06 & 0.13 \\
\hline SF & $-0.42^{*}$ & $-0.47^{\star}$ & -0.21 & -0.18 & -0.35 \\
\hline RE & -0.32 & -0.12 & 0.17 & 0.23 & 0.06 \\
\hline $\mathrm{MH}$ & -0.26 & -0.40 & -0.15 & -0.05 & -0.19 \\
\hline PCS & -0.24 & $-0.63^{*}$ & $-0.59^{*}$ & $-0.54^{*}$ & $-0.65^{*}$ \\
\hline MCS & -0.36 & -0.26 & 0.06 & 0.15 & -0.02 \\
\hline
\end{tabular}

VAS: visual analogue scale, NDI: neck disability index, SPADI: shoulder pain disability index, PF: physical functioning, RP: role physical, BP: bodily pain, GH: general health, VT: vitality, SF: social functioning, RE: role emotion, MH: mental health, PCS: physical component scale, MCS: mental component scale. ${ }^{*} p<0.05$. 
\pm 9.7 세) 및 대상자 포함 기준이(목과 어깨의 통증으로 인한 불편감을 호소하는 정도) 유사하였다. 그러나, Hwang과 Mun은 VAS 4.65 5.30 $\mathrm{cm}$, NDI 20.81점, SPADI 51.93\%, Osborn과 Jull27 은 VAS $5.10 \mathrm{~cm}$, NDI 33.8 점으로 본 연구와 차이를 보였다. 이러한 결과의 차이는 Hwang과 $\mathrm{Mun}^{7}$ 의 연구에서는 대상자의 나이가 평균 48.8 세였으며 의학적 진 단을 받은 사람들이 대상자라는 것과, Osborn과 Jull ${ }^{27}$ 의 연구에서 통 증의 위치가 목과 팔이라는 점에서 차이가 나타난 것으로 사료된다. $\mathrm{VAS}$ 는 통증 자각 증상을 대상자가 직접 표시하는 지표로 주관적인 느낌을 반영한다면 NDI나 SPADI는 통증이 있는 대상자가 일상생활 동작을 할 때 느끼는 불편함을 여러 항목으로 종합한 값이다. 따라서 본 연구의 대상자는 목과 어깨의 통증이나 불편함에 대해 의학적 진 단을 받거나 목과 어깨의 특정 질환을 가지고 있는 환자가 아니었고 다른 선행연구에서는 의학적 진단을 통해 일상생활의 불편함을 느 끼는 사람을 대상으로 하여 이러한 차이가 나타났다고 생각된다.

본 연구에서 통증과 장애 정도의 상관관계를 분석한 결과 통증 정 도와 장애 정도는 양의 상관관계가 있음을 시사하였다. VAS와 NDI 는 중간 정도의 양의 상관관계를 나타내었고 VAS와 SPADI는 약한 양의 상관관계를 나타내었으나 통계적으로 유의하지 않았다. 그러나 $\mathrm{NDI}$ 와 SPADI는 중간 정도의 양의 상관관계를 나타내었고 통계적으 로 유의한 차이를 나타내었다. 이러한 결과를 바탕으로 목과 어깨의 통증이 증가함에 따라 일상생활의 장애와 불편함이 증가한다고 할 수 있다. 또한 목의 통증과 불편함은 어깨의 통증과 불편함과도 관련 성을 가지며 목의 통증과 불편함이 증가하면 어깨의 통증과 불편함 이 증가한다고 할 수 있다. 이와 같은 결과를 뒷받침할 수 있는 선행연 구들로는 VAS와 NDI 사이의 상관관계를 분석한 Hermann과 Reese $\mathrm{e}^{28}$ 와 $\mathrm{McCarthy}$ 등 ${ }^{29}$ 의 연구가 있으며 각각 $\mathrm{r}=0.65, \mathrm{r}=0.50$ 의 중간 정도 의 양의 상관관계를 보고하였고 본 연구의 결과 $(\rho=0.34, p>0.05)$ 보다 는 높은 상관성을 나타내었다. 이와 같은 상관성의 차이는 본 연구의 대상자 수가 24명으로 작았고 정규분포를 가정하지 못하였으나, 이 들 선행연구의 대상자는 80 명, 160 명으로 표본이 크고 정규분포를 가 정하여 본 연구의 상관관계보다는 높은 상관성을 나타낸 것으로 생 각된다. 또 하나의 선행연구로 $\mathrm{NDI}$ 와 SPADI 사이의 높은 상관성 $(\mathrm{r}=0.79)$ 을 보고한 연구도 있다.

또 다른 중요한 결과로는 목과 어깨의 통증과 장애 정도에 따른 삶 의 질 관련성을 살펴본 결과, VAS와 NDI, SPADI는 SF-36의 하위 영역 인 PCS, MCS와 음의 상관관계를 나타내었다. 특히 PCS가 NDI, $\mathrm{SPADI}$ 와 통계적으로 유의한 음의 상관관계를 나타내었고 $(\mathrm{p}<0.05)$, $\mathrm{MCS}$ 는 통계적으로 유의하지 않았다. Hermann과 Reese ${ }^{28}$ 는 VAS와 $\mathrm{PCS}(\mathrm{r}=-0.41), \mathrm{MCS}(\mathrm{r}=-0.30)$ 가 중간 정도의 음의 상관관계를, $\mathrm{NDI}$ 와 $\mathrm{PCS}(\mathrm{r}=-0.67), \mathrm{MCS}(\mathrm{r}=-0.39)$ 역시 중간 정도의 음의 상관관계를 보 고하여 본 연구와 가장 유사한 결과를 나타내었다. NDI의 한국어판
개작을 수행한 국내 연구 역시 본 연구의 결과와 유사한 결과를 보고 하였다. ${ }^{30}$ Song 등 30 의 연구에서는 VAS와 NDI는 $\mathrm{r}=0.489$ 의 양의 상관 관계를 나타내었고, VAS와 PCS ( $\mathrm{r}=-0.321), \mathrm{MCS}(\mathrm{r}=-0.423)$ 는 중간 정 도의 음의 상관관계를, $\mathrm{NDI}$ 와 $\mathrm{PCS}(\mathrm{r}=-0.515), \mathrm{MCS}(\mathrm{r}=-0.372)$ 는 중간 정도의 음의 상관관계를 나타내었다. 그 외에도 목 통증과 삶의 질의 관계를 보고한 연구들은 목 통증의 정도에 따라 삶의 질을 다중 회 귀 분석한 결과 SF-36 항목 중 PCS만 목 통증과 관련을 나타내었고 $\mathrm{MCS}$ 는 목 통증과 관련성이 없었다.12,31 이와 같은 결과는 PCS가 VAS 를 제외한 NDI와 SPADI와 중간 정도의 음의 상관관계를 나타내었고 통계적으로 유의한 결과를 나타낸 반면, MCS는 다른 지표들과 약한 음의 상관관계를 나타내었으나 통계적으로 유의하지 않아 목과 어깨 의 통증과 장애는 정신적인 삶의 질 부분보다는 신체적인 삶의 질과 관련성을 가진다고 해석한 본 연구의 결과와도 일치하였다. Hill 등 32 은 SPADI와 SF-36의 상관관계를 분석한 결과 PCS $(r=-0.46), \mathrm{MCS}$ $(\mathrm{r}=-0.24)$ 와 음의 상관관계를 나타내어 본 연구의 결과와는 약간의 차이가 있었다. 또한 국내 연구진 중 Hwang과 $\mathrm{Mun}^{7}$ 의 연구 결과는 $\mathrm{VAS}$ 와 $\mathrm{NDI}, \mathrm{SPADI}$ 의 상관관계가 중간에서 강한 양의 상관관계를 나 타내었다 $(r=0.4 \sim r=0.8)$. 이들의 결과는 본 연구의 결과와 차이가 있 었는데 그 이유는 SPADI 점수 산정 방법이 본 연구와 달랐고 안타깝 게도 삶의 질과의 상관성을 측정하지 않아 더 이상의 해석은 불가능 하다고 생각된다.

또 한가지 눈에 띄는 결과는 목과 어깨의 통증과 장애 정도를 측정 한 VAS와 NDI, SPADI 중에서 특히 NDI가 SF-36 하위 영역들과 중간 정도의 음의 상관관계를 나타낸 것이다. 본 연구에서는 VAS나 SPADI 는 SF-36의 8 개 하위 영역들과 약한 양의 상관관계를 나타낸 영역들도 있었고 통계적으로 유의하지 않은 결과를 나타내기도 하였다. 그러나 NDI는 SF-36의 8개 하위 영역과 모두 음의 상관관계를 나타내었고 통 계적으로 유의한 관련성을 가진 항목들은 $\rho=-0.47 \sim \rho=-0.64$ 의 상관 관계를 보여 다른 항목들의 상관성에 비해 높은 상관관계를 나타내었 다. 이와 같은 결과는 NDI가 SF-36의 하위 영역들과 $r=-0.45 \sim r=-0.74$ 의 음의 상관성을 보고한 연구 결과와 일치하였다. ${ }^{29}$ 그들은 NDI가 척 추 수술 환자들의 통증을 평가하고 삶의 질에 관련성을 설명하기에 적절한 신뢰도와 타당도를 가지고 있음을 보고하였다.

본 연구의 제한점으로는 설문 조사의 표본 크기가 작았고 목과 어 깨의 통증과 장애를 진단받은 환자가 아닌 주관적으로 통증과 불편 함을 느끼는 사람을 대상자로 선정하여 모집단 전체로 일반화하기 에는 어려움이 있다는 것이다. 또 하나의 제한점은 장기적인 코호트 연구가 아닌 단면 연구로 목과 어깨 통증을 나타내는 환자들에게 일 반화하기에도 어려움이 있다는 것이다. 향후 이러한 제한점들을 보 완하여 코호트 연구나 치료 효과에 대한 무작위 임상시험 연구가 이 루어지길 기대한다. 


\section{참고 문헌}

1. Koh MJ, Park SY, Park EJ et al. The effect of education on decreasing the prevalence and severity of neck and shoulder pain: a longitudinal study in korean male adolescents. Korean J Anesthesiol. 2014;67(3):198-204.

2. Kim YG, Kang MH, Kim JW et al. Influence of the duration of smartphone usage on flexion angles of the cervical and lumbar spine and on reposition error in the cervical spine. Physical Therapy Korea. 2013; 20(1):10-7.

3. Lee MH, Song JM, Kim JS. The effect of neck exercises on neck and shoulder posture and pain in high school students. J Kor Phys Ther. 2011;23(1):29-35.

4. Nam KS, Kwon JW. The effects of head position in different sitting postures on muscle activity with/without forward head and rounded shoulder. J Kor Phys Ther. 2014;26(3):140-6.

5. Cote P, Cassidy JD, Carroll LJ et al. The annual incidence and course of neck pain in the general population: a population-based cohort study. Pain. 2004;112(3):267-73.

6. Jung HJ, Song YM, Kim HY et al. Prevalence and associated factors of neck shoulder pain in high school students. Korean J Fam Med. 2008;29(8):595-603.

7. Hwang S, Mun MH. Relationship of neck disability index, shoulder pain and disability index, and visual analogue scale in individuals with chronic neck pain. Physical Therapy Rehabilitation Science. 2013;2(2):111-4.

8. Roach KE, Budiman-Mak E, Songsiridej N et al. Development of a shoulder pain and disability index. Arthritis Care Res. 1991;4(4):143-9.

9. Vernon H, Mior S. The neck disability index: a study of reliability and validity. J Manipulative Physiol Ther. 1991;14(7):409-15.

10. Miettinen T, Leino E, Airaksinen O et al. The possibility to use simple validated questionnaires to predict long-term health problems after whiplash injury. Spine (Phila Pa 1976). 2004;29(3):E47-51.

11. Jimenez Bunuales MT, Gonzalez Diego P, Martin Moreno JM. international classification of functioning, disability and health (icf) 2001. Rev Esp Salud Publica. 2002;76(4):271-9.

12. Nolet PS, Cote P, Kristman VL et al. Is neck pain associated with worse health-related quality of life 6 months later? A population-based cohort study. Spine J. 2015;15(4):675-84.

13. Tunwattanapong P, Kongkasuwan R, Kuptniratsaikul V. The effectiveness of a neck and shoulder stretching exercise program among office workers with neck pain: a randomized controlled trial. Clin Rehabil. 2016;30(1):64-72.

14. Sihawong R, Janwantanakul P, Sitthipornvorakul E et al. Exercise therapy for office workers with nonspecific neck pain: a systematic review. J Manipulative Physiol Ther. 2011;34(1):62-71.

15. Koh SB, Chang SJ, Kang MG et al. Reliability and validity on measurement instrument for health status assessment in occupational workers. Korean J Prev Med. 1997;30(2):251-66.

16. Carlesso LC, Walton DM, MacDermid JC. Reflecting on whiplash associated disorder through a qol lens: an option to advance practice and re- search. Disabil Rehabil. 2012;34(13):1131-9.

17. Lucas Carrasco R. International perspective on quality of life in older adults. The whoqol old project. Vertex. 2007;18(72):130-7.

18. Wan C, Fang J, Jiang R et al. Development and validation of a quality of life instrument for patients with drug dependence: comparisons with sf36 and whoqol-100. Int J Nurs Stud. 2011;48(9):1080-95.

19. Ware JE, Jr., Sherbourne CD. The mos 36-item short-form health survey (sf-36). I. Conceptual framework and item selection. Med Care. 1992;30(6):473-83.

20. McHorney CA, Ware JE, Jr., Raczek AE. The mos 36-item short-form health survey (sf-36): ii. Psychometric and clinical tests of validity in measuring physical and mental health constructs. Med Care. 1993;31(3):247-63.

21. Garratt AM, Ruta DA, Abdalla MI et al. The sf36 health survey questionnaire: an outcome measure suitable for routine use within the nhs? Bmj. 1993;306(6890):1440-4.

22. Ziebland S. The short form 36 health status questionnaire: Clues from the oxford region's normative data about its usefulness in measuring health gain in population surveys. J Epidemiol Community Health. 1995;49(1):102-5.

23. Li L, Liu X, Herr K. Postoperative pain intensity assessment: a comparison of four scales in chinese adults. Pain Med. 2007;8(3):223-34.

24. Vernon H. The neck disability index: state-of-the-art, 1991-2008. J Manipulative Physiol Ther. 2008;31(7):491-502.

25. McHorney CA, Ware JE, Jr., Lu JF et al. The mos 36-item short-form health survey (sf-36): iii. Tests of data quality, scaling assumptions, and reliability across diverse patient groups. Med Care. 1994;32(1):40-66.

26. Ma C, Szeto GP, Yan T et al. Comparing biofeedback with active exercise and passive treatment for the management of work-related neck and shoulder pain: a randomized controlled trial. Arch Phys Med Rehabil. 2011;92(6):849-58.

27. Osborn W, Jull G. Patients with non-specific neck disorders commonly report upper limb disability. Man Ther. 2013;18(6):492-7.

28. Hermann KM, Reese CS. Relationships among selected measures of impairment, functional limitation, and disability in patients with cervical spine disorders. Phys Ther. 2001;81(3):903-14.

29. McCarthy MJ, Grevitt MP, Silcocks P et al. The reliability of the vernon and mior neck disability index, and its validity compared with the short form-36 health survey questionnaire. Eur Spine J. 2007;16(12):2111-7.

30. Song KJ, Choi BW, Kim SJ et al. Cross-cultural adaptation and validation of the Korean version of the neck disability index. J Korean Orthop Assoc. 2009;44(3):350-9.

31. Rezai M, Cote P, Cassidy JD et al. The association between prevalent neck pain and health-related quality of life: a cross-sectional analysis. Eur Spine J. 2009;18(3):371-81.

32. Hill CL, Lester S, Taylor AW et al. Factor structure and validity of the shoulder pain and disability index in a population-based study of people with shoulder symptoms. BMC Musculoskelet Disord. 2011;12:8. 